\title{
SIGNIFICANCE OF THE BEHAVIOR OF SENSITIVE STIGMAS ${ }^{1}$
}

\author{
F. C. Newcombe \\ (Received for publication June II, I92I)
}

It has been known for a long time that in the families of the Bignoniaceae, Scrophulariaceae, Martyniaceae, and Lentibulariaceae there are certain genera whose stigmas respond to pressure. In nature, the stimulating object is the body of a visiting insect or of a humming bird. The external structure of these sensitive stigmas is similar, though not closely similar, in all species. The stigma consists, in most of the species, of two tongueshaped lobes which ordinarily diverge $180^{\circ}$ or more. The pollen is deposited on the inner surface of these gaping lobes by the visiting insect, and the push of the insect's body stimulates the lobes to close together completely, except in the Lentibulariaceae, in which there is but partial closing.

\section{The Primary Closing of Stigmas}

\section{Stimuli Causing Primary Closing}

As stated above, the primary closing of stigmas includes that striking behavior in which the two divergent stigma lobes close together as a result of the pressure of an insect or other body, the response being therefore thigmotropic.

As long ago as $\mathrm{I} 84 \mathrm{I}$, sensitive stigmas were described by Henderson ( $\mathrm{I}$ ), and in I86I by Kabsch (2). More recently some dozen authors have published their observations and experiments, till, at the present time, we know some two dozen species and varieties with sensitive stigmas. A list of these species, with the names of authors publishing them, .will be found under the "Summary," at the end of this paper.

The notion that the stigmas are anywhere sensitive (or responsive) to the slight pressure called touch is erronerus, as shown by Lloyd (I4) for Diplacus glutinosus, and as I: have found for six species I have tested. A human hair may be glued to a style, leaving two centimeters free, and with the tip of the hair one may stroke the stigmas anywhere without causing closing. I have commonly used this instrument in the pollination tests, the hair carrying the pollen very well.

To locate the sensitive region of the stigma, various authors have explored the stigma lobes with various instruments. Heckel (8) found both stigma lobes equally sensitive, but the inner surfaces of the lobes more sensitive than the outer surfaces. Oliver (I0), working in part with the

${ }^{1}$ Contribution 184 from the Botanical Department of the University of Michigan. 
same species as Heckel, found the stigma lobes sensitive on the inner faces only: Burck (12) found both surfaces sensitive, but the inner surface the more so. Lloyd (14), by probing the stigma of Diplacus glutinosus with a dull-pointed glass rod, was convinced that the lobes are sensitive on their inner faces only, and that a response is brought about only when the cells of the inner faces are stretched by the bending of the lobes.

My own work in determining the location of the sensitive area of the stigma has been done on Catalpa bignonioides, Tecoma radicans, Torenia fournieri, and Utricularia vulgaris. In Catalpa, the lobes are sensitive on both the inner and outer surfaces, though more sensitive on the inner. In the other three species, the lobes are sensitive on their inner surfaces only. To determine this result, the following method was used, except for Utricularia, which has but one sensitive lobe, the other being small and not motile. The flower was secured with its pedicel between the halves of a cork held by a clamp. The corolla and stamens were then removed. Next, one lobe of the stigma was seized by a fine forceps and bent back out of the way of the other lobe, the object being to prevent the two lobes coming into contact during the manipulation. With any kind of a blunt probe, one may now explore the free lobe for the sensitive region. By this method, the lobes of Tecoma, Torenia, and Utricularia may be pushed about at willfrom 20 to 50 flowers were used for each species-as long as the probe is against the outer surface only; or percussion may be used on the outer surface without bringing a response. The same sort of treatment will, however, cause the prompt closing of the stigmatic lobes of Catalpa. The sensitiveness of Catalpa to pressure on the outer faces of the stigmatic lobes shows that the condition for reaction that Lloyd found for Diplacus glutinosus-the stretching of the cells of the inner face of the stigma-does not obtain for all species; for one can hardly believe that pressure on the back of the lobe will cause the elongation of cells on the inner face. The question must be left open, however; as to whether the stimulus on both the outer and the inner faces of the stigma of Catalpa is due to pressure or to stretching of cells on the respective faces.

That the body giving the stimulus need not be solid has been shown by obtaining the same responses when using a fine jet of air against the stigma lobes of Tecoma radicans, Torenia fournieri, and Utricularia vulgaris.

Besides the pressure stimulus, there is no doubt that an electric current through the stigmas may induce the primary closing. Kabsch (2) notes this for Mimulus guttatus, and I have had the same result with Catalpa bignonioides. Heckel (8) records the vapors of hydrocyanic acid, acetic acid, 'ammonia, chloroform, ether, etc., as inducing primary closing, and Correns (II) found the same for ammonia vapor and reduced oxygen pressure. Lloyd (I4), however, showed that heat, alcohol vapor, and liquid alcohol cause the closing of the stigma of Diplacus glutinosus only as they kill the stigma. I have found the same relations. in the behavior of 
the stigma of Catalpa bignonioides toward ammonia vapor. By normal pressure stimulus, my Catalpa in first class condition at $29^{\circ} \mathrm{C}$. will begin closing in 2 seconds and completes its closing in 7 seconds from the moment of stimulation. In strong ammonia vapor, at $29^{\circ} \mathrm{C}$., the stigmas began closing in $\mathrm{I} 5$ to 20 minutes. One flower, on removal from the vapor after a 5 minutes' stay, showed its stigma normally sensitive to pressure. The stigmas of the other flowers left in the ammonia vapor were still closing slowly 55 minutes after being placed in the vapor, and were completely closed and dead 70 minutes after being placed in the vapor. Lloyd's results with heat and alcohol and my own with ammonia vapor raise the question whether Heckel's (8) results, obtaining closing with these same agents and others, were really sensitive responses, as he thought, or rather the result of the death of the protoplasm. Of course, one must bear in mind the fact that many contractile organs, like the leaves of Mimosa, respond in a sensitive way to ammonia vapor and to other poisonous vapors and gases; so that, a priori, one might expect the stigmas to close in the presence of various vapors and gases.

Another method of stimulating for Catalpa bignonioides consists in crushing a portion of the style. Burck (12) states that the styles of the species he worked with could be cut through without causing the stigma to close. Many trials of the same kind were made with the Catalpa I worked with and no closing ensued, if the knife was sharp, no matter where the style was cut. If, however, scissors were used, and the cut was not more than 2.5 millimeters from the insertion of the stigma lobes, the most sensitive stigmas at $30^{\circ}$ would close after the lapse of 5 to 15 seconds. Crushing the style with forceps whose tips were one millimeter wide was a much surer way of causing closing. In one series of 21 pistils, the style crushed with the forceps $10 \mathrm{~mm}$. from the insertion of the lobes, temperature $29^{\circ}$, the stigmas closed at periods 15 to 120 seconds from the time of crushing. In another series of Io pistils, style crushed as above noted at a distance of $2.5 \mathrm{~mm}$. from the insertion of the lobes, temperature $29^{\circ}$, closing took place in 5 to $\mathrm{I} 6$ seconds from the time of crushing. These two series with their results are fairly representative of the whole number of tests. Pinching the style between finger and thumb will often, but not always, cause the stigmas to close. As a result of the pinching, no injury to the style could be detected-no deformation nor infiltration.

When one considers the time of the response when the style was crushed at Io millimeters, and again at $\mathbf{2 . 5}$ millimeters from the stigma lobes, it would seem that the closing, probably due to sudden increase of waterpermeability in the cells of the stigma lobes, must have been induced by an impulse received from the injured protoplasm of the style. The change in permeability of the contracting cells in the stigma could hardly be due to the sudden flow of water toward the crushed spot of the style, for there was no closing when the style was cut through with a razor; nor could it 
be due to the forcing of cell sap into the stigma when crushing the style, for the response came too long after the crushing to be so accounted for.

The stigma of Mimulus glabratus var. Jamesii also could be stimulated by crushing the style 2 millimeters from the insertion of the lobes, though the closing was never complete, and the lobes started to retrace their course 2 to 3 minutes after the crushing of the style.

\section{Relative Sensitiveness and Transmission of Stimuli in Various Species}

Heckel (8) attempted to arrange the 9 species that he studied in a series according to the sensitiveness of the stigma, citing Martynia and Mimulus as among the most sensitive and Tecoma, Bignonia, and Catalpa among the least sensitive. The Martynia stigmas he saw complete their closing in 3 seconds after stimulation, while the stigmas of the 3 genera named above as less sensitive required 60 seconds.

During the several years of my observations, I have watched the closing of thousands of stigmas, with not fewer than scores of observations in any of four genera and nearly a score in each of two species in another genus (Mimulus). Though I have made no special study of the relative reaction time of various species, I am certain that the response of Catalpa bignonioides is, under favorable conditions, completed in 7 seconds, that of Torenia fournieri in 2 seconds; of Tecoma radicans in 3 seconds at $30^{\circ}$; of Mimulus glabratus var. Jamesii in ro seconds at $2 \mathrm{I}^{\circ}$; while even the slowest of the eight species I have observed has shown individual closures within 12 seconds of stimulation. I have seen, on one tree of Catalpa bignonioides growing in good soil, stigmas close in 7 seconds, while on another tree, stunted and in poor dry soil, the stigmas required 60 seconds or more to close. The following season, flowers were found on the latter tree whose stigmas closed in ro seconds. The responsiveness of the stigmas, as is the case with sensitive reactions generally, is so influenced by external and internal conditions, that only a special study can determine the relative sensitiveness of the stigmas of species; and such a study has not yet been made.

Perhaps it is remarkable that so few species of the Scrophulariaceae have been reported to have sensitive stigmas, seeing that there are so many that have the two-lobed form of stigma characteristic of those that are sensitive. It would seem probable that search will discover other species sensitive, and different degrees of sensitiveness. A little attention on my part has been given to the testing of other species for sensitiveness, but, of the several examined, only Digitalis purpurea and a hybrid, Digitalis purpurea $\& \times D$. lanata $\sigma^{7}$, have given any response. The response is relatively feeble in both cases. In $D$. purpurea, generally no movement of stigma lobes could be detected. On one occasion, when the stigmas of seven flowers were given the pressure always bringing a response in Mimulus and the other plants already mentioned, four stigmas showed a slight closing 
movement, the lobes traveling $10^{\circ}$ to $15^{\circ}$. The hybrid, in 20 or more stigmas tested, showed a larger number of responses, about half the stigmas moving $20^{\circ}$ to $80^{\circ}$. The stigmas of these plants never close, and the small movements noted can be of no benefit to the plant.

Quite another topic on which considerable work has been done is the transmission of stimuli. Heckel (8) simply states that the stimulus is transmitted from one lobe to another, without giving his method for determining such transmission. Burck (12) believed that the stimulus was not transmitted in the eight species he worked with. Oliver (I0), by holding one lobe of the stigma with forceps so that it could not press against the other lobe, determined that the stimulus is not transmitted from one lobe to the other in Mimulus luteus, but is transmitted in Mimulus cardinalis, Martynia lutea, and Martynia proboscidea. Lloyd (14) found the stimulus not only transmitted from one lobe to the other in Diplacus glutinosus, but not even transmitted from one part to another of the same lobe. The stigma of Catalpa bignonioides also shows no transmission of stimulus from one lobe to the other, as I have proved many times by using Oliver's method; but in the lobe stimulated, the impulse travels apparently over the whole lobe from the minute area where the stimulus may be applied. In Mimulus punctatus, not many flowers were available for trial, but the six stigmas used showed no transmission of stimulus from one lobe to the other. In Torenia fournieri there is also no transmission of stimulus from one lobe to the other, as I ascertained by numerous tests.

We may thus feel fairly. certain that in some species the stimulus is transmitted from lobe to lobe, while in others it is not; and that in the same genus, as in Mimulus, one species may show transmission and another may not.

\section{Significance of Primary Closing}

It is a matter of common observation that sensitive stigmas of all species reopen a few minutes after closing, provided that no pollen is deposited at the time of stimulation. The behavior of pollinated and closed stigmas has, however, been described by very few authors. Burck (12) states that all of the eight species he worked with; except Torenia fournieri, kept their stigmas continuously closed after first closing at the time of pollination; and Torenia stigmas remained closed if the pollen used on the stigmas was dry. Elrod ( $\mathrm{I}_{3}$ ) found the pollinated and closed stigmas of Tecoma radicans nearly always remaining closed, and always remaining closed if fertilization ensued. On the other hand, Lloyd (14) records the stigmas of Diplacus glutinosus as opening regularly, shortly after forcible pollination, to close again permanently some hours later.

In all of the seven species whose stigmas I have tested for opening after forcible pollination, I have found all the stigmas opening in two species and some of the stigmas opening in each of the five other species. In Utricularia 
vulgaris all seven flowers used opened their stigmas 20 to 65 minutes after forcible pollination. In Mimulus glabratus var. Jamesii the eight stigmas which were pollinated and closed subsequently opened, four of them within 30 minutes, and the other four probably in about the same time, though observation was not made till Io hours after the first closing, when the four were all wide open. Having but a few flowers of Mimulus punctatus, I used but one stigma for the present purpose. This stigma opened ro minutes after forcible pollination. In the species Mimulus cardinalis nine forcibly pollinated stigmas were obseryed for subsequent behavior. Eight of these stigmas opened in periods ranging from 20 to 150 minutes after closing, the earlier opening taking place in a temperature of $28.5^{\circ}$, the later in $12.5^{\circ}$. The plant used was in the open garden and was protected from insects by a cheesecloth net. In the species Torenia fournieri, twenty stigmas were forcibly pollinated and closed. Eleven opened in 20 to 70 minutes, and nine remained closed. This is the same species used by Burck (12) and found by him to keep its stigma closed with dry pollen and to open the stigma after moist pollen was used. In my hands the stigmas of this species opened after using either dry or moist pollen; but I shall return later in this paper to the matter of the influence of moisture on closing. Twenty-seven flowers of Tecoma radicans were observed for the behavior of forcibly pollinated stigmas. Twenty-six of these stigmas remained closed and only one opened. In the species Catalpa bignonioides, 89 stigmas were observed after being pollinated and closed by the pressure stimulation. Some of these tests were made in sunshine and some in shade, some in dry air and some in moist, and in temperatures from $18^{\circ}$ to $32^{\circ}$. The general summarized result gives 39 stigmas opening after the first closing and 50 remaining continuously closed. In very moist air, the most of the pollinated and closed stigmas of Catalpa and Torenia will reopen.

Inasmuch as none of my experiments here recorded were given conditions that might not obtain in nature, it follows that the stigmas of all my seven species tested may reopen in appropriate natural conditions, after their closing at the time of pollination by the usual natural agent. One may believe that not only these seven species and the Diplacus, as found by Lloyd (I4), but also all the other related species known to have sensitive stigmas may at times show their stigmas opening after the first closing, and subsequently closing again. These relations are justification for speaking, as in this paper, of primary and secondary closing of the stigmas.

As the primary closing of stigmas, even when pollinated, is in Utricularia vulgaris and Mimulus glabratus generally, and may be in other species not infrequently, followed in 15 to 60 minutes by opening, it is necessary to assume that the biological significance of the primary closing is likely to be some immediate good in the life of the plant. F. Müller (4), Hildebrand (5), Batalin (6), H. Müller (7), Darwin (9), and Elrod (13) have 
assumed that the closing of the stigma serves the plant in preventing its own pollen from reaching the stigma, the visiting insect causing the stigma to close before the insect reaches the pollen of the same flower. This view would seem to express the obvious significance of the phenomenon. The only objection to this interpretation has been raised by Burck (12) who states that in Torenia fournieri the visiting bee encounters the pollen before touching the stigma. I have examined the position of anthers and stigma in hundreds of flowers of Torenia fournieri, and have never seen a case in which a visiting bee would touch the pollen before the stigma. This does not imply that Burck may not have seen such cases; for the species of Torenia, Catalpa, Tecoma, and Mimulus that I have examined show considerable variation in the position of anthers and stigma, though in the great majority of cases the well known relation is present of one pair of anthers far above, the other pair below, and the stigma between the two pairs and projecting in front of them; or the stigma rises above all the anthers, and projects forward into the open throat of the flower. In flowers of Catalpa bignonioides and Mimulus cardinalis, I have seen in a few instances stigmas covered with pollen from anthers pressing in between the open stigmatic lobes. But these unusual relations cannot be cited as evidence against an hypothesis supported by the evidence of the usual behavior. F. Müller (4) found the flowers of Tecoma sp., Elrod (13) found those of Tecoma radicans, and. Batalin (6) those of Mimulus guttatus infertile to their own pollen. On the other hand, I found Torenia fournieri, Mimulus cardinalis, and Utricularia vulgaris readily self-fertile, and one case of self-fertilization in Catalpa bignonioides.

\section{The Secondary Closing of Stigmas}

As stated earlier in this paper, the opening of stigmas, which often occurs after the primary closing at the time of insect pollination, has not been generally observed. The usual statement is that the stigmas remain permanently closed provided pollen has been deposited at the time of closure. This statement is true for some species only; for other species, under certain conditions there may be an opening of stigmas following the first closing, and later another closing without a second stimulation.

\section{Phenomena as Observed in Nature}

The species Utricularia vulgaris differs in its stigma structure from all other species so far reported to have sensitive stigmas, in that it has but one motile lobe. Only the lower lobe is long and motile, while the upper lobe is short and rigid. A description of this stigma may be found in Hildebrand's (5) paper. When the lower lobe of the Utricularia stigma is mechanically stimulated and pollen is deposited upon it, it immediately.rises through an arc of $180^{\circ}$ or more, but does not close against the upper lobe, there 
being left a small open chamber between the two lobes. This motile lobe, however, soon begins to retrace its course, so that in 20 to 30 minutes it is near or in its first position. Mimulus glabratus var. Jamesii is another species-this one with the usual two subequal and motile lobes-that, in its usual behavior, opens its stigma lobes a few minutes after the first closing at the time of pollination. Lloyd (I4) found the same behavior with Diplacus glutinosus. We thus know of three species that, in their usual behavior, open their stigmas soon after the first closing at the time of pollination. Possibly other species will be found to behave in the same way. In preceding pages, I have reported four species whose stigmas do not always open after the first closing with pollination, but may open and later show secondary closing.

Of the 24 species and varieties now known to possess sensitive stigmas, 15 have been tested to determine whether pollen could be placed on the stigma without causing the stigma to close immediately, and with all 15 the test has been successful. In 13 of the 15 species, however, the majority of the stigmas of each species in usual weather close 2 to 5 hours after the application of the pollen. Stigmas, therefore, may show the secondary, without showing the primary, closing.

\section{Significance of Secondary Closing}

An extensive series of experiments in my own work with Catalpa bignonioides and with Torenia fournieri, as well as less extensive tests with several other species, have demonstrated the fact that the pollen does not germinate on the stigma, unless the stigma lobes are closed, except in unusually moist air.

A number of tests of the time of germination of the pollen of Catalpa resulted in showing that in Io percent sugar solution at $29^{\circ}$, initial pollen tubes could be found after 3 hours, at $23^{\circ}$ after $33 / 4$ hours, good germination with long tubes after 6 hours at $23^{\circ}$, and 80 percent germination at $26^{\circ}$ after $81 / 2$ hours. Pollen from freshly opened anthers germinates well, and pollen adhering to open anthers retains its viability for three days or more after dehiscence.

The great majority of stigmas of Catalpa left on the tree close whether pollinated or not. If the blossoms are brought into the house and placed in a damp chamber, some stigmas will close, but some will remain open continuously even though pollen may be placed on the lobes. In a series of eight experiments, the stigmas of 48 blossoms were cross-pollinated so as not to cause closing of the lobes, and the blossoms were kept with their stalks in water in a moderately moist chamber at $22^{\circ}$ to $26^{\circ}$. Of the 48 stigmas used, 22 remained open continuously for 24 to 26 hours, when they were examined for germination of pollen. . There was no germination of pollen. Eight flowers had their stigmas cross-pollinated without closing the stigmas, and the flowers, dipping into water, were kept in a chamber 
nearly saturated with moisture for 26 hours, at $23^{\circ}$. In this period none of the stigmas closed. Pollen germination as high as 75 percent was shown on all stigmas. Of the 48 stigmas mentioned above as cross-pollinated and kept in a moderately moist chamber, 26 closed or partially closed 3 to ro hours after pollination, but not one of them remained closed continuously for the 24 hours or more of the experiment. All of these stigmas showed pollen germination estimated in the different individuals at from ro percent to 75 percent, the percentage of germination varying with the degree of closure or with the duration of the closure of the stigmas.

The stigmas of Torenia fournieri proved themselves less influenced by dryness of air than did those of Catalpa. When a potted plant bearing blossoms was kept in moderately moist air, pollinated stigmas generally remained open if the pollination was so done as to avoid primary closing, or the stigmas opened in 30 to 60 minutes if they had been stimulated to close at the time of pollination. In three series of tests in which some of the stigmas had closed and so remained, while others had opened or remained open, microscopic examination at the end of 24 hours showed the pollen ungerminated on the open stigmas, but germinated on the closed ones. A more extensive series of tests was made with this same species in which the growth of ovules was used as the criterion for the growth of pollen on the stigma. In one series, during damp weather, I 3 stigmas were given pollen without causing closing, the plant being kept outdoors under a net screen in natural atmosphere. The stigmas did not close, and there was no fertilization. In another test, six flowers had pollen placed on their stigmas without closing. The pot was kept on wet ground outdoors under a net-covered wire cage covered with a wet blanket nights, and with water falling on the net during the day. The plant must have been in a nearly moisture-saturated atmosphere continuously, though no water fell on the plant. The preparation was kept going for six days without closing of stigmas. At the end of this period, all six ovaries showed abundant, large ovules.

A similar test to the foregoing, except that the chamber holding the plant was kept only moderately moist, was made with six pollinated flowers. Of these, four stigmas closed $4 \% 2$ to 14 hours after pollination, remained closed I 2 to 14 hours, opened or partly opened for the next 3 to Io hours, then closed permanently. The ovaries of these four showed good growth with a good supply of ovules eight days after pollination. The other two stigmas half closed about 12 hours after pollination and so remained between 7 and Io hours, then opened and so remained. The ovaries of these two flowers after 8 days had grown but little and contained but a few enlarged ovules. The pollen used on the foregoing six stigmas was all taken from the longer pair of stamens of one flower. The flowers were constantly protected from insects by a cheesecloth net.

Nine flowers of Tecoma radicans were brought into the laboratory where 
[Vol. 9.

the air was cooler and more moist than outdoors. The open stigmas were pollinated all from a mixture of pollen from two anthers of another flower. Five stigmas were caused to close at once by stimulating, and four were pollinated without closing. All the stigmas maintained, till microscopical examination the next day, their original closed or open position. The five closed stigmas showed their pollen well germinated, but the four open stigmas showed no germination of pollen.

With Mimulus cardinalis, only one experiment is pertinent for entry here. Four stigmas were given pollen and closed by the pressure stimulus. The plant bearing the flowers was in the gairden, and was covered with a cheesecloth net. The weather for the first three days was moist and ranged from $12.5^{\circ}$ to $2 \mathrm{I}^{\circ}$. The first stigma remained closed throughout; I2 days after pollination the ovary was large and had abundant ovules. The second stigma was closed on pollination but opened after two and a half hours, remained open a day and then closed finally; twelve days after pollination the ovary was about two thirds full size and had about half the normal number of ovules. The third stigma was closed on pollination and remained closed throughout; examination twelve days after pollination showed a normal-sized ovary filled with ovules. The fourth stigma was closed at the time of pollination, but opened in an hour and did not close again; at the end of the twelve days, the ovary had grown to less than half the size of the preceding one, and had one fourth as many ovules. In the last case there must have been germination of some of the pollen on the open stigma. This germination could be accounted for by the moist atmosphere which prevailed for the two days following pollination.

From the results obtained with the foregoing four species, representing four genera, there can be no doubt that the continued closure or the secondary closure of the pollinated stigmas serves the plant in securing germination of pollen on the stigma. Of the eight species which have been under my examination, only Utricularia vulgaris has shown fluid on the stigma. Lloyd (14) reports Diplacus as having no stigmatic fluid. The value of the closure of the stigmas in promoting pollen germination would seem obvious, and the experimental results confirm the assumption.

\section{Cause of Secondary Closing}

As stated before in this paper, the stigmas of some of the two dozen species of plants known to possess sensitive stigmas reopen in less than an hour after they have been closed at the time of pollination. These stigmas, except in Mimulus glabratus and Utricularia vulgaris, close again within 2 to 14 hours, unless the weather is unusually damp. Some stigmas in several of the species do not open after the primary closing at the time of pollination, and hence the effect is the same as though there were opening followed by secondary closing. The question now to be considered is the cause of the continuance of the primary closure, and of the secondary closure when there has been an opening after the primary closure. 


\section{a. Effect of the Germination of Pollen on the Stigma}

It cannot be the germination of pollen followed by the penetration of pollen tubes into the tissue of the stigma that causes the stigma to remain closed after the primary closing. For I have found none of the pollens, under the most favorable conditions, on the stigmas or in sugar solutions, germinating in less than two hours. Indeed, in only three tests have I found it germinating in less than six hours. The stigmas, however, of all species so far reported by others, as well as those under my own observation, open in most cases, in temperatures of $18^{\circ}$ or above, within 30 minutes of the primary closing, provided no pollen has been placed on the stigmas. In such time relations, it may be assumed that the pollen has some effect in keeping the stigmas closed; but it cannot be the germination of pollen. Nor can it be the germination of pollen which causes the secondary closing of the stigmas; for, in the first place, many examinations of mine have shown that the pollen does not germinate on stigmas in ordinary weather till the stigmas have closed; and, in the second place, when pollen does germinate on stigmas in very moist air, the stigmas do not close.

\section{.b. Withdrawal of Water from the Stigmatic Cells}

Burck (12) found that if he pollinated the stigma of Torenia fournieri with dry pollen and closed the stigma, the stigma remained closed; but if he used moist pollen the stigma soon opened again. From this behavior, he inferred that it was the withdrawal of water from the stigma that kept the stigma closed.

Lloyd (I4), by observing the local curvature of the stigma lobes of Diplacus glutinosus when pollen masses were placed on different spots on the inner surfaces, came to the same conclusion as Burck.

Brown (I5), using Martynia proboscidea, could load the stigma lobes with sand or could give them a little quartz flour without causing closing. When, however, he used a large quantity of quartz flour, the stigma closed. From this behavior, he inferred, with Burck and Lloyd, that it is the withdrawal of water from the cells on the inner side of the lobes that causes the secondary closing.

My own rather extensive work on the cause and conditions of secondary closing may be narrated under three sub-headings.

I. Relation of closing to atmospheric moisture. Among the several species reported in this paper, two distinguish themselves from the others in that the bilabiate corolla has a closed throat, and the plants themselves grow in water or only where the substratum is very wet. These species are Utricularia vulgaris and Mimulus glabratus var. Jamesii. Seven individual flowers of the former and eight of the latter were cross-pollinated and the stigmas closed, but all stigmas opened soon afterward and did not subsequently close. Nevertheless the ovules of Utricularia were fertilized; but 
the behavior in Mimulus was not followed long enough to determine this matter. Yet it cannot be doubted that the pollen germinates on the open stigmas of the Mimulus and that fertilization results. Pollen germination on the open stigma of Utricularia was determined by teasing out several stigmas some hours after pollination. Besides the seven cases, specially tested as noted above, many other stigmas of Utricularia were seen to have the lower lip recurved (open) after the fall of the corolla. Yet all these flowers bore seeds.

The other species subjected to experiment and observation have open flowers and hence do wot keep moisture about their stigmas sufficient, in usual weather, to promote germination. It would, perhaps, be correct to say that they do not keep sufficient moisture about their stigmas to allow, or cause, reopening after the primary closing, or to prevent the secondary closing in case there has been a secondary opening. Especially careful observations for determining these relations have been made with Torenia fournieri and Catalpa bignonioides. The general result has been the failure of secondary closing in very moist air and the occurrence of secondary closing in dry air. Six stigmas of Torenia, pollinated and not closed, kept outdoors under a fine net, weather $23^{\circ}$ to $26^{\circ}$, not very moist, all closed in $4 \frac{1}{2}$ to 14 hours. Six other stigmas, pollinated and not closed, the plant kept day and.night outdoors in a nearly moisture-saturated chamber, in good light by day, temperature $23^{\circ}$ to $26^{\circ}$, did not close at all. Seven other stigmas were cross-pollinated and closed at II A.M. on a sunny summer's day, and the potted plants were set outdoors in the sun under a fine net. Four of the stigmas soon opened at the tips of the lobes, but closed again during the next few hours. At 7:50 P.M. six of the seven were well closed, and the seventh was half closed. The plants were then brought into the house and kept in moister air over night. In the morning, four stigmas were open, the other three closed. The stigmas of thirteen flowers had small masses of pollen placed on the stigmatic surface near the tips of the lips, and the plants were kept outdoors under a fine net. The weather was moderate and clear, fairly dry, with day temperature $22^{\circ}$ to $28^{\circ}$. The stigmas were not closed at first and did not close subsequently. They were watched for two days after pollination. Besides these series of experiments, many pollinations and closings of stigmas were made, generally resulting, unless a damp chamber was employed, in the pollinated stigmas remaining closed permanently.

Generally, if the air is moist and the sky clouded, one will find the stigmas of Catalpa bignonioides open while the flowers are still on the tree. On the other hand, in sunshine, especially in the afternoon, the most of the stigmas are closed. The closing could be referred to the effect of the dry air, or to insect pollination, or to a combination of the two things. To determine whether the stigmas would close in usual weather, the open flowers were removed and discarded from several panicles on a part of the 
tree but little reached by the sun, and paper bags were tied over the panicles. The following day the bags were removed. The open flowers were then always found with open stigmas. Several panicles were brought into the laboratory and their stems were set in water. The open flowers were discarded, and a wait was made for the immature blossoms to open. When the blossoms were open and stigmas were open, the inflorescences were subjected to conditions which brought wilting, or to conditions preventing wilting. The result reached was that the stigmas close, without stimulation or the presence of pollen, as soon as the corollas shrw any wilting. The corollas show flagging very quickly in experimentation; and quite generally in natural conditions on the tree-such temperature and moisture conditions as obtain the latter part of June and through July, when the trees are in bloom-the corollas are found flagging and the stigmas closed. My observations on the closing of the unpollinated stigmas because of wilting and the readiness with which incipient wilting takes place in the usual behavior of these flowers have extended to hundreds of flowers and have covered three flowering seasons.

Assuming that the stigmas of Catalpa close without pollination, with incipient wilting of the flower, as shown in the preceding paragraph, one may next inquire whether the presence of pollen on the stigma will cause closing when there is no wilting. My notes show that 109 flowers have

- been used in trying to answer this question. It was found that if, after pollination without immediate closing. of the stigma, precautions were taken to insure a very moist atmosphere, there was no subsequent closing. In an atmosphere not very moist yet moist enough to prevent wilting of the flower, the presence of pollen induced closing when in its absence there would have been no closing.

With the flowers of Tecoma radicans, I 7 stigmas were cross-pollinated without closing the stigmas immediately. The flowers were kept in the house, their pedicels dipping into water in beakers. The conditions were, therefore, fairly moist and there was no wilting. Only one of the I 7 stigmas subsequently closed. Several unpollinated flowers lay on the table without water for ro hours, and thus were allowed to wilt; but they showed no closing of the stigma. This series of tests is incomplete. It needs still the case of pollination, without primary closing, in dry air, or with flowers on the vine, to see whether the secondary closing would ensue. That the presence of pollen on the stigma is effective in keeping the stigma closed after it has been stimulated mechanically to close was shown by Elrod (13); and numerous tests of my own confirm his results.

2. Use of absorbent substances on the stigma. As stated before in this paper, Burck (I2), Lloyd (I4), and Brown (I5) have expressed the view that the secondary closing of stigmas is due to the withdrawal of water from the inner surface of the stigma lobes by the pollen. There is no question that the presence of pollen in dry air either keeps the stigma closed 
after the primary closing, or induces a secondary closing if there has been a secondary opening or if there has been no primary closing. It should be recalled here that the two species Utricularia vulgaris and Mimulus glabratus var. Jamesii are exceptional in that the stigmas show no secondary closing. It may also be recalled that the other species reported in this paper show much oftener than hitherto supposed both secondary opening and a failure of secondary closing, especially in moist air.

Moist and dry pollen. Only I 9 stigmas were used-7 of Torenia fournieri and 12 of Catalpa-in comparing the effect of moist and of dry pollen on maintaining the closed condition of stigmas. The result cannot be said to be conclusive, but only indicative. When the atmosphere was dry, the stigmas receiving dry pollen remained closed longer than those receiving moist pollen, or a larger proportion of the former remained permanently closed. When the atmosphere was moist, the most of the stigmas opened without distinction between dry and moist pollen. The dry and moist pollens were always used at the same time on similar flowers, the dry being taken in some cases from anthers open 24 or more hours, while the moist was taken from unopened anthers. Or, in other cases, both pollens were taken from the same anthers, open 24 or more hours, the pollen applied dry to some anthers and moistened with spring water before being applied to others.

Wheat flour. Four open stigmas of Torenia were given a fair amount of wheat flour, and closed. The plant bearing the flowers was kept in the house where the moisture was considerable. All stigmas began opening in 30 minutes. In 90 minutes, all were fully open.

Ten stigmas of Catalpa, while the flowers were still on the tree, were covered with wheat flour and made to close. The temperature was $27^{\circ}$, and the air fairly moist, but the sky clear. Cheesecloth bags were drawn over the panicles. After 3 hours, 5 stigmas were still closed, and the other 5 were open slightly from the tips of the lobes to their insertion. The next observation was made the next morning, 18 hours after the stigmas were closed; all but one stigma were open. Three stigmas, as controls, were closed but given no flour at the same time as the last 10, and were otherwise given the same treatment. All three were wide open when observed two and three fourths hours after closing, and still open 18 hours after closing. Eighteen flowers of Catalpa were plucked, placed in a damp chamber and brought into the house, where the temperature was the same as outdoors, $23^{\circ}$; there had been showers, and the air was fairly moist. Eleven stigmas were given a thin coating of wheat flour, and 7 stigmas a heavy coating, and all stigmas were closed in the act of applying the flour. After 150 minutes, 7 were closed, 2 were open, and 2 were one third open of those receiving but a thin cover of flour. Of the 7 stigmas receiving a thick cover of flour, 4 were closed and 3 were open $30^{\circ}$, 150 minutes after the first closing. Six hours after the flour was applied, of the II receiving little flour, 6 were 
closed, and 5 were open; of those receiving much flour, 4 were closed and 3 were open. Seventeen hours after the flour was applied, of the I I receiving little flour, 5 were closed, 5 were wide open, and one was open $45^{\circ}$; of the 7 receiving much flour, 4 were closed, and 3 were open $90^{\circ}$ to $200^{\circ}$.

Sixteen stigmas of Tecoma radicans were given dry wheat flour, and closed, the blossoms being kept in the house, standing in water in beakers. The behavior of 7 of these stigmas was followed for 3 days. Six of them remained continuously closed, and one opened during the night, at some time within I2 hours of closing. Of 7 other stigmas, of the group of I6, 6 remained closed and one opened during 4 hours, when observations were discontinued. The other 2 stigmas, one hour after receiving flour and closing, were open $60^{\circ}$ and $90^{\circ}$ respectively, but were fully closed two and one half hours after receiving the flour.

That the presence of the flour had the effect of keeping the stigmas of Tecoma closed was demonstrated by the behavior of several controls used at the same time as some of the 16 stigmas whose behavior has just been followed. Five stigmas were caused to close without being given anything; all opened within an hour and remained open during the 6 hours of observation.

Mimulus glabratus var. Jamesii, it will be recalled, has a closed flower, and its stigmas do not remain closed after pollination. Flour was used on Io stigmas of this species, and the results showed that flour neither causes the stigmas to close, nor does it prolong the closure if one closes the stigmas at the time the flour is applied.

From the foregoing results, the stigmas of Mimulus glabratus and of Torenia fournieri, as far as the evidence goes, seem to behave in about the same way when given flour as when given pollen. That is, neither pollen nor flour keeps the stigmas closed. The stigmas of Tecoma and of Catalpa are certainly affected by the flour in that a larger proportion remain closed if given flour than if given no flour; but the flour does not keep so many closed as does the pollen. The difference in behavior with pollen and with flour is especially marked $\mathrm{I} 2$ to 20 hours after the primary closing: with pollen, the stigmas are likely to remain closed; but with flour the stigmas generally open finally.

Starch. Wheat flour was heated to $80^{\circ}$ in tap water to destroy the enzyme. It was then washed 3 times to remove the protein. The starch obtained was dried and applied to the stigmas of 9 flowers of the Catalpa. The preparation was kept in the house. After 3 hours 4 were open, 4 were closed, and one was open $30^{\circ}$. Twelve hours after applying the starch, all stigmas were open. Twelve other stigmas were given dry starch and all stigmas were stimulated to close. This preparation also was made in the house. After one hour, I I stigmas were open, the other closed. This condition continued for 5 hours at least, and the next observation was made the next morning, 17 hours after the starch was applied. All I2 stigmas 
were then open. As a control for the last preparation, 9 stigmas were pollinated and closed. The Catalpa flowers for this test were plucked at the same time as the preceding set that were given starch, and the two groups were carried on side by side. At the end of 75 minutes and of 135 minutes, 8 were open and one closed. Five and one quarter hours after pollination and the primary closing, 5 were closed and 4 open. After 16 hours from the beginning, 6 were closed and 3 were open.

In the preceding section, Tecoma was found to keep its stigmas closed when given wheat flour. A test with starch only, using two stigmas in flowers in the house, showed the starch keeping the stigmas closed for 23 hours, when observations were discontinued.

Emery powder. Very fine emery powder was washed in strong alcohol and later in several changes of water, and then dried. Large amounts of this powder were placed in the angle of the divergent lobes of eight stigmas of Tecoma radicans. The flowers bearing these stigmas were brought into the laboratory at noon, and set in beakers with their lower ends in water. The emery powder was applied at I :30 P.M. and the stigmas were immediately closed. At the same time six stigmas of flowers similarly treated were given wheat flour and closed. Observation was not made for four and one half hours, when all stigmas given emery powder were open, and all given flour were closed.

3. Living and dead pollen, enzymes, proleins. The foregoing results obtained with Tecoma, in the behavior of stigmas when applying emery powder compared with the behavior when applying wheat starch, and with Catalpa when using wheat flour compared with the behavior when using pollen, show that the flour exerts an influence not possessed by the emery powder, and the pollen exerts an influence not possessed by the flour. Other results have shown with Catalpa that wheat flour exerts a closing effect to a greater degree than the flour deprived of its protein. In attempting to solve some of the questions arising from these relations, one may assume that it is either the proteins or the enzymes in flour that make it more effective than starch, and that it is either the enzymes or the germination effects of pollen that make pollen more effective than flour and starch in inducing permanent closure of the stigmas.

To determine the difference in behavior of stigmas with living and with dead pollen, a quantity of pollen from recently opened anthers of Catalpa was covered with water at $88^{\circ} \mathrm{C}$. The water was decanted and the pollen grains were washed in water and dried at $60^{\circ}$. The pollen was then placed on 12 stigmas of flowers standing in water in the house, and the stigmas closed. The weather was warm and moist. Eleven of the stigmas opened within an hour. In three hours all were open. Seventeen hours after applying the pollen, all stigmas were still open. There were no controls made at the same time as the foregoing tests, but the day before, under similar conditions, four stigmas of Catalpa were given living pollen and 
closed. In one hour and three quarters, two stigmas were open $30^{\circ}$ at the tips, the other two were closed. Five and three quarter hours after pollination, all were closed. The next morning, I6 hours after pollination, all were closed. Many other tests made with living pollen show that this result obtained with four stigmas is usual, and there can be no doubt that dead pollen is much less effective than living pollen in keeping the stigmas of Catalpa closed.

To test the action of an enzyme directly, the commercial Taka-diastase was used on the stigmas of Catalpa and Torenia. Thirteen flowers of Catalpa, sitting in a little water in the house, temperature $26^{\circ}$, moisture medium, had the Taka-diastase powder inserted into the angle of their divergent stigma lobes by using a little wooden rod whose tip was sharpened to a wedge. The stigmas closed immediately. After one hour, all were closed except one, which was well open. The same condition continued for 6 hours, the time of the last observation of the day. The next morning, I 8 hours after the closing of the stigmas, 5 stigmas were open and 8 were closed. In another test, ro stigmas of Catalpa, flowers treated as was the last set were given a mixture of one fourth Taka-diastase and three fourths starch. All stigmas remained closed for the rest of the day's observations, or for 6 hours. The next morning, 18 hours after the stigmas closed, 5 were closed and 5 were open.

At the same time that the foregoing experiments were being conducted, I I flowers of Catalpa, treated as were the other flowers, had pollen placed on their stigmas, and the stigmas closed. After 2 hours, 6 were open and 5 closed. An hour later, 4 were open and 7 closed. The next morning, I 3 hours after pollination, 4 were open and 7 closed; but one that had been open the evening before was now closed, and one that had been closed was now open. This experiment was made as a control for the preceding. It here shows the diastase acting as well as the pollen in keeping the stigmas closed. The Taka-diastase is known to contain both diastase and hemicellulase.

In an attempt to ascertain whether it was the enzyme content or the protein constitution of the Taka-diastase that kept the stigmas closed, the enzyme was destroyed by heating some of the powder in water at $80^{\circ}$ and subsequently evaporating at a temperature of $50^{\circ}$. The resultant horny mass was powdered, but found to kill some of the stigmas when applied to them. Some of this powder was, therefore, mixed with three times its volume of corn starch, and the mixture was applied to the stigmas of 13 flowers of Catalpa. The flowers were kept with their bases sitting in water in the house; the experiment was made the day following the preceding one. One hour after applying the mixture and closing the stigmas, all were still closed. Two hours after the beginning, all were closed; 5 hours after the beginning, 6 were open and 7 closed; 9 hours after the beginning, ro were open and 3 closed; I I hours after the beginning, Io were open and 3 closed; 
the next morning, or 20 hours after the first closing, Io were open and 3 closed. At the time of the last record, 2 that had been open had closed, and 2 that had been closed had opened.

Several potted plants of Torenia fournieri that were kept outdoors under fine nets were used in testing the action of Taka-diastase. On I6 stigmas was placed a mixture of one fourth of the diastase whose enzyme had been destroyed by heating and three fourths corn starch. The mixed powder was dry when applied, and all stigmas were closed in the application. After one hour Io were open and 6 closed; after 2 hours, i I were open and 5 closed; after 4 hours, 12 open and 4 closed. The next morning, 14 hours after the first closing, I3 were open and 3. closed. Sixteen other stigmas, used at the same time as the preceding 16 and on the same plants, were given a mixture of one fourth normal Taka-diastase and three fourths corn starch. After one hour, 5 were open and I I closed; after 2 hours, 6 were open and Io closed; after 4 hours, 7 were open and 9 closed. The next morning, I4 hours after the first closing, I 2 were open and 4 closed.

The foregoing tests with Torenia give a very good indication that the presence of the enzyme has an effect in keeping the stigmas closed longer than the same substance when the enzyme has been destroyed; but, after the lapse of I4 hours, about as large a proportion of stigmas opened with enzyme as with the de-enzymized material.

Eight stigmas of Torenia on a plant outdoors under a fine net were given commercial casein and closed. The weather was sunny and fairly dry. All stigmas opened within 20 to 40 minutes of closing. Observations were not made to see how much earlier they may have opened. These stigmas were repeatedly closed by stimulating after the first closing, but all reopened as often as they were artificially closed. Observations continued for 17 hours.

Twelve stigmas of Torenia, weather cloudy and moist, were given a mixture of one fourth Witte's peptone and three fourths corn starch. All opened promptly and remained open for 4 hours at least, when observation was ended.

\section{SUMMARY}

In all, 25 species and varieties of plants have been reported, 4 of them for the first time in the present paper, with sensitive stigmas. These 25 plants are included in 4 families. The stigmas are composed of two tongueshaped lobes of equal or unequal size which diverge $90^{\circ}$ to nearly $360^{\circ}$ when ready for pollination. The receptive region for pollen is the inner or apposed surfaces of the two lobes, except for Utricularia in which only the lower lobe receives the pollen.

The natural stimulus for the stigmas is the pressure of the body of the visiting insect or other animal, and the response consists in the closing together of the two lobes, so that the two lobes, except in the case of Utric- 
ularia, are in contact over the most or the whole of their inner surfaces. It requires an appreciable pressure to call forth a response, and pollen may be artificially applied to the stigmas without causing closing. Besides pressure, the stigmas will respond to an electric current, stigmas of some species to various vapors perhaps, and the stigmas of Catalpa bignonioides and Mimulus glab, atus var. Jamesii to crushing of the style, or to pinching of the style.

As far as good evidence goes, the most of the species so far reported show a sensitiveness to pressure on the inner surface only. In my own work, Catalpa bignonioides showed itself sensitive on both the outer and the inner surfaces of the stigma lobes, though more sensitive on the inner surface. The conduction of a stimulus from one stigma lobe to another has been determined positively for only the three species so reported by Oliver-Martynia lutea, $M$. proboscidea, and Mimulus cardinalis. On the other hand, Lloyd found the stigma of Diplacus glutinosus, and my study showed the stigmas of Catalpa bignonioides, Mimulus punctatus, and Torenia fournieri not transmitting the stimulus from one lobe to the other.

As to the degree of relative sensitiveness, or the speed of response, in the various species, little that is certain can be said. It is certain that Digitalis purpurea is the slowest of all reported; but the stigma of this species does not carry out an effective closing, and it should not be considered in the same class as the others. Most of the stigmas whose time of response has been reported have shown a complete closing within Io seconds of the time of stimulation. Stigmas, reported by Heckel as the slowest in response, I have found the quickest, namely, those of Torenia closing com. pletely in 2 seconds, and those of Tecoma in 3 seconds after stimulation. But the responses of all stigmas vary so much with temperature and other conditions that a statement of relative sensitiveness is not now possible.

The obvious benefit to the plant of the closure of the stigma is its aid in securing cross-pollination. As the stigmas are generally in such a position as to be touched by the insect, or other visitor, before the pollen of the same flower is encountered, and as the stigmatic surface is in a few seconds after touching turned so as to be out of reach of the flower visitor as he withdraws, self-pollination can be possible only in those rare cases of very slowly acting stigmas or unusually placed stigmas.

The present study has shown that the phenomenon of stigmas opening soon after pollination is more general than hitherto supposed. We knew from the work of Lloyd that Diplacus glutinosus regularly opened its stigma after closing at the time of pollination. The study here reported shows that the stigmas of Utricularia vulgaris and Mimulus glabratus also always open after pollination, that the stigmas of Torenia fournieri and Catalpa bignonioides sometimes open in not very dry air, and half of them, or more, will open in moist weather. Other species have shown stigmas opening in moist air after being closed at the time of pollination. 
After the primary closing at the time of pollination, the stigmas that open close again 2 to Io hours after the opening, unless the air is very moist. The significance of this secondary closing is well indicated by the fact that pollen will not germinate on the open stigma unless the air is well nigh saturated. Utricularia vulgaris and Mimulus glabratus var. Jamesii, having closed flowers, do not keep their stigmas closed after closing at the time of pollination, but the pollen germinates on the open stigma lobes. Except for the two species just mentioned, the germination of the pollen on the stigmas is secured either by continuous closure of the stigmas from the time of pollination, or by a secondary closing in those cases in which the stigmas open after pollination.

As is well known, the sensitive stigmas under consideration reopen as often as closed, provided no pollen has been placed on the stigmatic surface. When pollen is placed on the stigma and the lobes are closed, the stigma may open within an hour, as it regularly does in Diplacus, or it may never open again, as is usual in Tecoma and frequent in several other species. Also the pollen may be artificially placed on the stigma so gently as not to cause closing. In this last case, the stigma remains open for two to ten hours, and then closes unless the air is very moist. In any event, the stigma is usually closed to hours after pollination. By what agency is the primary closing maintained, and the secondary closing caused? It has been suggested by previous writers that the withdrawal of water by the pollen is the cause of the closing, and that the phenomenon is purely physical. Numbers of experiments have been reported in this paper which seem to me to indicate that the continued closure of the stigmas is more than the simple abstraction of water. Inorganic powder, like emery flour, is not effective at all in keeping the stigmas closed, though by capillarity it should withdraw water from the closed stigma. Pollen killed in hot water and dried does not keep the stigmas closed, though it retards somewhat their opening. Wet pollen and dry pollen keep the stigmas closed equally well. Flour and starch keep the stigmas of Tecoma closed about as well as does living pollen, but the stigmas of Torenia and Catalpa open finally when given flour or starch. The enzyme known as Taka-diastase, either in pure powder or mixed with starch, causes the stigmas of Torenia and Catalpa to remain closed for 3 to ro hours, but nearly all the stigmas finally open. The Takadiastase, with its enzyme destroyed by hot water, then evaporated, powdered, mixed with starch, and placed on stigmas, keeps the stigmas closed a shorter time than does the mixture of the normal Taka-diastase and starch. Casein alone does not affect the closure of the stigmas of Torenia, nor does a mixture of peptone and starch. This statement of results with different species shows how impossible it is to generalize by the study of a single species, and it might be that the behavior of several similarly acting species would not lead to a correct interpretation applicable to all.

The one statement which seems possible to make is that, with the ex- 
ception of Tecoma radicans, none of the species reported in this paper keep their stigmas closed as long with any other substance tried as with living pollen. The behavior of the stigmas of the various species tested in the present study indicates the possibility of an enzyme, or other chemical, in the pollen and Taka-diastase as the agent in maintaining closure. Starch alone is certainly effective in prolonging the closure; so that an enzyme, or similar chemical, need not be credited alone with influence on maintaining closure. It is difficult to conceive of the pollen maintaining closure or causing closure for days merely through the abstraction of water. Is there any reason why the stigmatic cells should not replenish their lost water by calling on the water supply in the style and parts below? Although the stigmas of Catalpa usually close at the beginning of wilting of the flower, the stigmas of other species do not close on wilting of the flower, and the stigmas remain open even when withering. . A loss of water by the cells of the stigma, therefore, does not necessarily require the lobes to close. It is true that if pollen, flour, and starch take water from the stigma, they take it probably from one side; but we do not know that these objects certainly take more water from the cells than the cells can recover. It does not seem likely either that the absorbing objects continue their water abstraction for hours. It would seem probable that the presence of absorbing material on the stigmatic surface reduces the resistance of the protoplasm to filtration, and that this loss of resistance is gradually recovered except in the case of germinating pollen. Such an increase and maintenance of permeability, even, though the effect comes slowly, may be a sensitive reaction instead of what is usually called a purely physical reaction, as has been suggested.

List of Plants Reported as Having Sensitive Stigmas, with the Authors' Names.

Several authors have reported plants, giving the genus only; such are not listed here except in two cases in which no species of the genus has been published. Several of the plants listed are horticultural varieties; but I have given the names as published by the authors of the papers.

SCROPHULARIACEAE

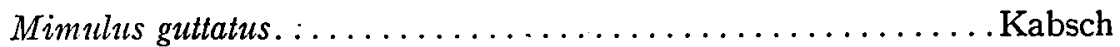

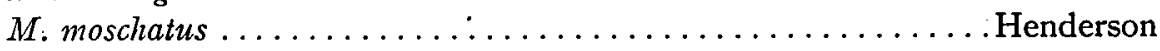

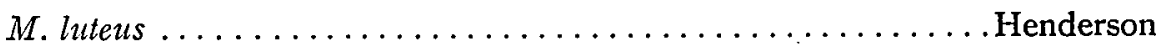

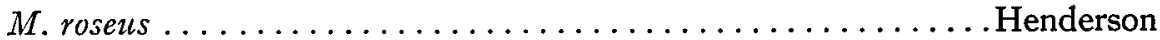

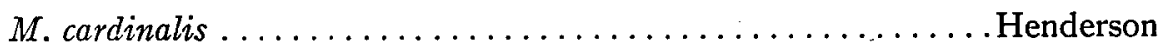

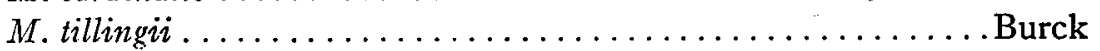

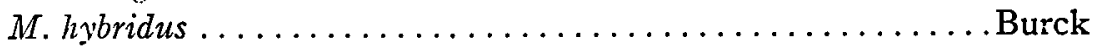

M. luteus L. var. punctatus. . ............... Newcombe

M. glabratus KBK. var. Jamesii T. \& G.............. Newcombe

Torenia Fournieri. ....................... . . .

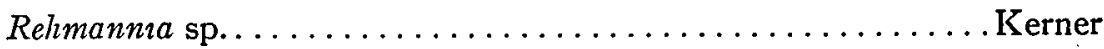

Digitalis purpurea L.................... Newcombe 
Martyniaceae

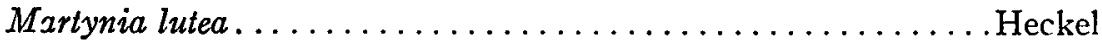

M. probossidea .......................................

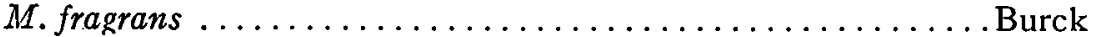

$M$. formosa ................................ Burck

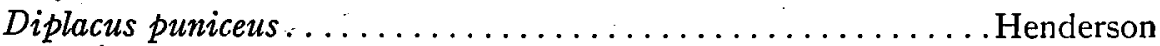

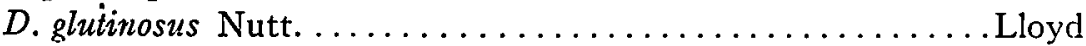

Bignoniaceae

Bignonia sp................................. Delpino

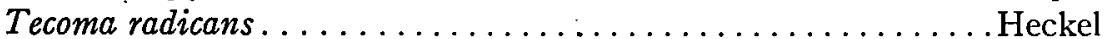

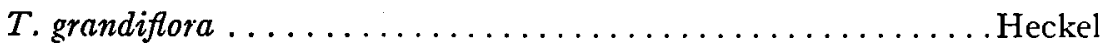

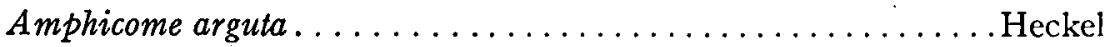

Incarvillea Delavayi............................ Burck

Catalpa bignonioides Walt....................... Newcombe

C. syringifolia .......................................

LENTIBULARIACEAE

Utricularia vulgaris ............................. Hildebrand

UNIVERSITY OF MICHIGAN, ANN ARBOR

\section{BIBLIOGRAPHY}

I. Henderson, J. On the structure of the stigma in Mimulus and Diplacus. Ann. Nat. Hist. 6: 5I. I84I.

2. Kabsch, W. Anatomische und physiologische Untersuchungen über einige Bewsgungserscheinungen im Pflanzenreiche. Bot. Zeit. 19: 36 . I86r.

3. Hildebrand, F. Federigo Delpino's Beobachtungen über die Bestä́ubungsvorrichtungen bei den Phanerogamen. Bot. Zeit. 25: 28. 1867.

4. Müller, F. Befruchtungsversuche an Cipó alho (Bignonia). Bot. Zeit. 25: 625. 1868.

5. Hildebrand, F. Weitere Beobachtungen über die Bestäubungsverhältnisse an Blüthen. Utricularia vulgaris. Bot. Zeit. 27: 505. 1869.

6. Batalin, A. Beobachtungen über die Bestäubung einiger Pflanzen. Bot. Zcit. 28: 53. 1870.

7. Müller, H. Die Befruchtung der Blumen durch Insekten. Leipzig, 1873.

8. Heckel, E. Du mouvement dans les stigmates bilabiés des Scrophularinées, des Bignoniacées et des Sésamées. Compt. Rend. Acad. Sci. Paris 79: 702. I874.

9. Darwin, C. The effects of cross and self-fertilisation in the vegetable kingdom. London, 1876.

10. Oliver, F. W. Ueber Fortleitung des Reizes bei reizbaren Narben. Ber. Deutsch. Bot. Ges. 5: 162. 1887.

II. Correns, C. Ueber die Abhängigkeit der Reizerscheinungen höherer Pflanzen von der Gegenwart freien Stickstoffes. Flora 75: 87. 1892 .

12. Burck, W. On the irritable stigmas of Torenia Fournieri and Mimulus lutens and on the means to prevent the germination of foreign pollen on the stigma. Kon. Akad. Wetensch. Amsterdam, Proc. Sect. Sci. 4: 184. 1902.

13. Elrod, M. N. Botanical notes. Proc. Ind. Acad. Sci. I903. II9. 1904.

14. Lloyd, F. E. Certain phases of the behavior of the stigma-lips in Diplacus glutinosus Nutt. Plant World 14: 257. 1911 .

15. Brown, W. H. The phenomenon of fatigue in the stigma of Martynia. Philip. Jour. Sci. C. Bot. 8: 197. 1913. 